\title{
INVESTIGATION OF HELIUM IMPLANTED Fe-Cr ALLOYS BY MEANS OF X-RAY DIFFRACTION AND POSITRON ANNIHILATION SPECTROSCOPY
}

\author{
Patrik Novák * Aleksandr Gokhman ${ }^{* *}$ \\ Edmund Dobročka ${ }^{* * *}$ — Jozef Bokor ${ }^{*}$ — Stanislav Pecko*
}

\begin{abstract}
X-ray diffraction (XRD) and positron annihilation spectroscopy (PAS) have been used for the characterization of the two binary alloys Fe-Cr with $\mathrm{Cr}$ content 2.36 and $8.39 \mathrm{wt} \%$. The influence of ion implantation on these alloys was studied. Different implantation doses of helium, up to $0.5 \mathrm{C} / \mathrm{cm}^{2}$, were used to simulate neutron-induced damage in a sub-surface region. To characterize the damage, a lattice parameter, coherent domain size, residual stress and a crystallographic texture have been studied by grazing incidence X-ray diffraction (GIXRD). It was found out that these parameters showed a similar dependence on the implantation dose as the positron lifetime determined by positron annihilation spectroscopy.

Keywords: grazing incidence, helium implantation, positron annihilation spectroscopy, radiation damage, x-ray
\end{abstract} diffraction

\section{INTRODUCTION}

A new generation of nuclear power plants requires more radiation resistant reactor materials. The most perspective materials for the new generation of fission reactors or thermonuclear fusion reactors are currently chromium ferritic/martensitic steels. In particular, these materials have to deal with high temperature and neutron flux. Important phenomenon is the hardening due to the effect of helium. Helium effectively stabilizes vacancy clusters, which means that less vacancies are available to recombine with interstitials, (iehelium ties up vacancies and reduces interstitial-vacancy recombination). Interstitial clusters can then grow into dislocation loops and increase the strength [1]. Chromium is a ferrite-stabilizing element that is generally added to the steels for an oxidation and corrosion resistance. The importance of this alloying element for the radiation-induced microstructural changes was discussed in the last decade $[2,3]$. Currently, it is studied using different experimental techniques as well as by computer simulations [4-7].

This paper shows a study of dependence of selected structural parameters on the implantation dose in the iron-based alloys with high and low chromium content (8.39 wt\% and $2.36 \mathrm{wt} \%$ ) under the radiation treatment. GIXRD is a suitable technique for observation of the implantation-induced damage in the sub-surface region. This technique in combination with the positron annihi- lation spectroscopy gives much information about structural changes in specimens after radiation treatment.

\section{EXPERIMENTS AND METHODS}

\subsection{Specimens and implantation}

All specimens were prepared at the Slovak University of Technology in Bratislava (see Ref. [8] for detailed information about the specimens). The chemical composition of the studied alloys is listed in Table 1.

Table 1. Chemical composition of the studied alloys in \%

\begin{tabular}{lllll} 
Alloy & $\mathrm{Cr}$ & $\mathrm{O}$ & $\mathrm{N}$ & $\mathrm{C}$ \\
\hline L251 & 2.36 & 0.035 & 0.012 & 0.008 \\
L252 & 8.39 & 0.067 & 0.015 & 0.021 \\
& & & & \\
Alloy & $\mathrm{P}$ & $\mathrm{Ni}$ & $\mathrm{Cu}$ & $\mathrm{V}$ \\
\hline L251 & 0.013 & 0.044 & 0.005 & 0.001 \\
L252 & 0.012 & 0.070 & 0.010 & 0.002
\end{tabular}

These Fe-Cr alloys have been cut to the size of $10 \times 10 \times$ $0.5 \mathrm{~mm}$, ground and polished to mirror-like surface before an exposure. The helium implantations at $250 \mathrm{keV}$ and 4 different levels of the implantation dose $(0.1,0.2,0.3,0.4$, $0.5 \mathrm{C} / \mathrm{cm}^{2}$ ) have been performed at the linear electrostatic accelerator of the Slovak University of Technology

Institute of Nuclear and Physical Engineering, Faculty of Electrical Engineering and Information Technology, Slovak University of Technology in Bratislava, Ilkovičova 3, 81219 Bratislava, Slovakia, patrik.novak@stuba.sk ** Department of Physics, South Ukrainian National Pedagogical University, 65020-Odessa, Ukraine ${ }^{* * *}$ Institute of Electrical Engineering, Slovak Academy of Science, Dúbravská cesta 9, 84104 Bratislava, Slovakia 


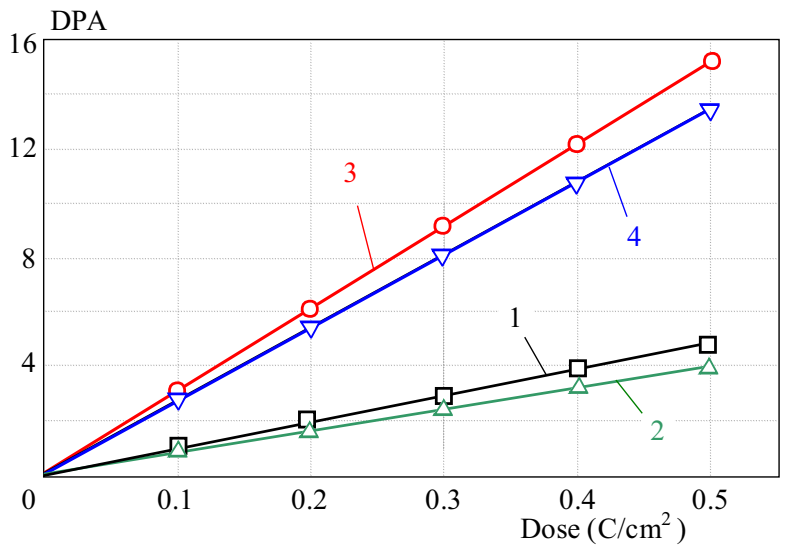

Fig. 1. DPA parameter of two binary alloys for depth of 0.3 and $0.6 \mu \mathrm{m}$

in Bratislava. The sample temperature was less than 343 $\mathrm{K}$ during implantation. Temperature of the sample holder was monitored by a thermocouple. The radiation damage in terms of the displacements per atom (DPA) simulated by the SRIM code [9] is presented in Fig. 1. The accelerator has a possibility to accelerate ions in a wide energy range from $10 \mathrm{keV}$ to $900 \mathrm{keV}$. The high-energy $\mathrm{He}^{2+}$ ion implantation is performed in a dedicated vacuum chamber.

The high-energy implantation beam-line consists of an entrance collimator, a switching magnet (10 degree branch), exit collimating slits, a beam diagnostic block and the implantation chamber [10]. The beam, after passing the switching magnet, is shaped by the exit collimating slits that define the size of the beam on the sample. The helium implantation was chosen due to participation of alpha particles on the radiation damage induced by fission or fusion reactions $[11,12]$.

\subsection{Analytical techniques}

\section{$\underline{X-\text { ray diffraction }}$}

$\mathrm{XRD}$ is a well-known non-destructive method for the evaluation of structural changes in materials. Diffraction measurements were performed in the parallel beam geometry with parabolic Goebel mirror in the primary beam at angle of incidence $2 \mathrm{deg}$, which corresponds to the penetration depth of approximately $0.3 \mu \mathrm{m}$. Bruker D8 DISCOVER diffractometer was used with X-ray tube equipped with a rotating $\mathrm{Cu}$ anode operating at $12 \mathrm{~kW}$. The measurements of the diffractograms were performed in a way that the angle of incidence, $\alpha$, was kept constant while the detector was moving along the $2 \Theta$ circle. All measurements have been performed in GIXRD setup at the Institute of Electrical Engineering, Slovak Academy of Sciences. For determination of the lattice parameter and the coherent domain size, the TOPAS software was used. The residual stress evaluation at different depths

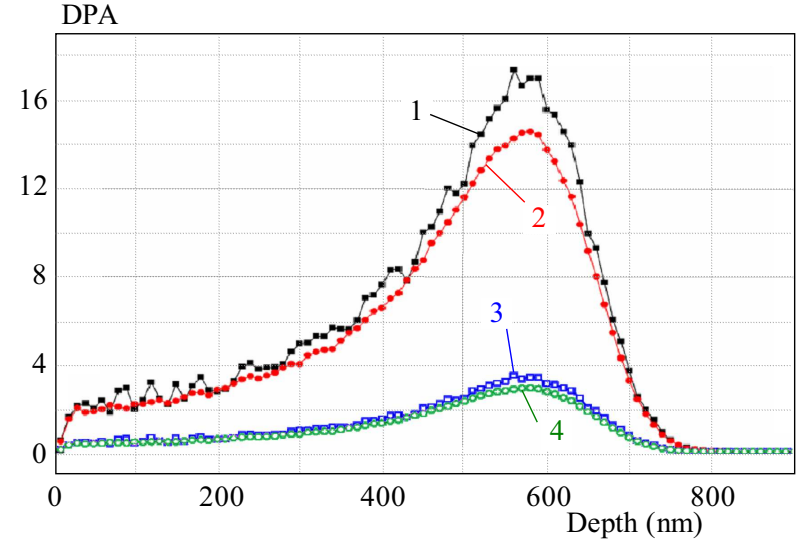

Fig. 2. DPA depth profiles from SRIM simulation, DPA/Dose: (1) $-2.36 \mathrm{wt} \% / 0.5 \mathrm{C} / \mathrm{cm}^{2},(2)-8.39 \mathrm{wt} \% / 0.5 \mathrm{C} / \mathrm{cm}^{2},(3)-2.36$ wt $\% / 0.1 \mathrm{C} / \mathrm{cm}^{2},(4)-8.39$ wt $\% / 0.1 \mathrm{C} / \mathrm{cm}^{2}$

was obtained using the conventional GI-sin $2 \psi$ method $[13,14]$.

\section{Positron annihilation spectroscopy}

The positron annihilation spectroscopy has been applied for the evaluation of the electron density by measuring the positron lifetime in the materials. These measurements have been carried out at the Slovak University of Technology in Bratislava. The used positron source, ${ }^{22} \mathrm{Na}$, has a continuous spectrum of positrons up to energy of $545 \mathrm{keV}$. All positrons annihilate within $100 \mathrm{~m}$ from the surface. The measurements of the positron lifetime were performed in a standard positron annihilation lifetime spectrometry (PALS) equipment using a twodetector setup. All the lifetime spectra could be decomposed into three lifetime components with variances close to one. In our study, we used only the second lifetime component, $\tau_{2}$, which describes positron annihilation in defects [15].

\section{RESULTS AND DISCUSSION}

In this paper, we are focusing on studying the influence of He-ion implantation on selected structural parameters of the steels with two different chromium-content levels. Helium-ion irradiation experiments can provide substitute for neutron irradiation [16]. Two Fe-Cr alloys with different $\mathrm{Cr}$ content have been investigated. The wellknown effect of chromium on the corrosion resistance of the steels is more pronounced for the specimen with higher Cr content [17-19]. This was the reason why we focused on comparison of two alloys with different $\mathrm{Cr}$ content in our studies. GIXRD and PAS showed that the lattice parameter, the coherent domain size, and the residual macrostress show similar dependence on the implantation dose as the positron lifetime in defects. For the quantification of radiation damage, the DPA parameter calculated by SRIM can be used (Fig. 2). 


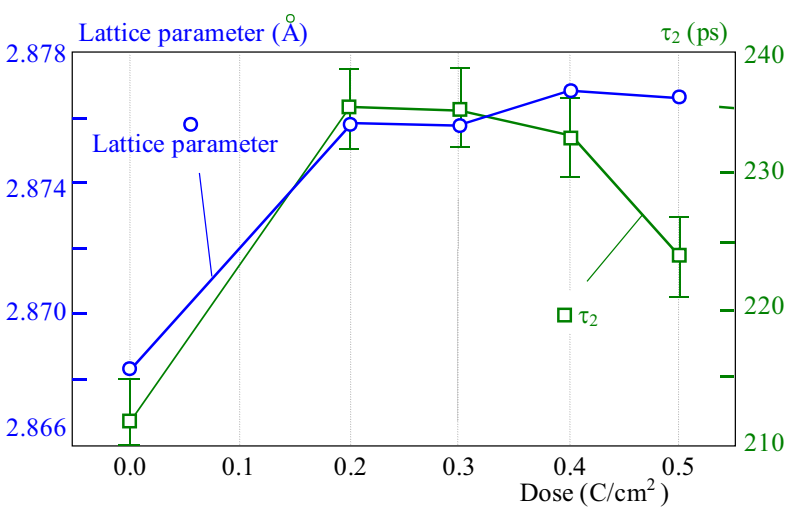

Fig. 3. The lattice parameter and positron lifetime in defects as a function of implantation dose in the sample with $2.36 \mathrm{wt} \% \mathrm{Cr}$

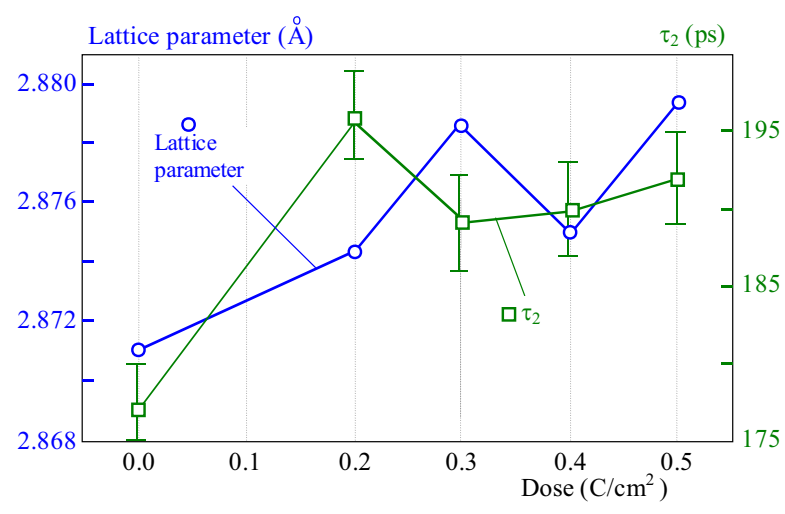

Fig. 4. The lattice parameter and positron lifetime in defects as a function of implantation dose in the sample with $8.39 \mathrm{wt} \% \mathrm{Cr}$
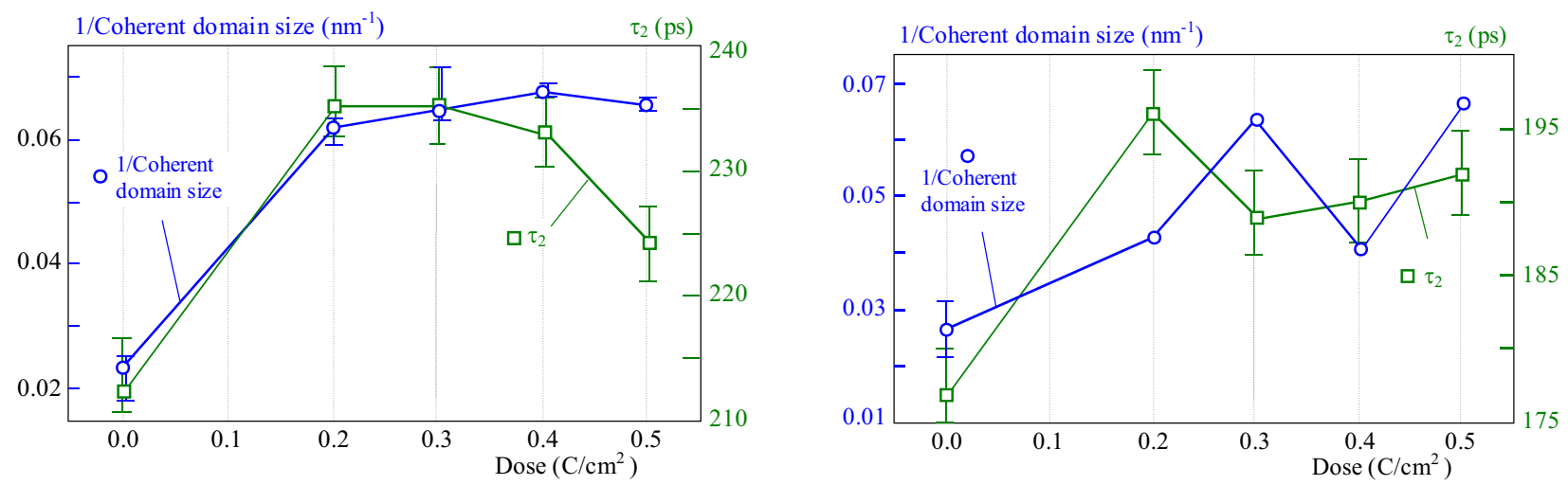

Fig. 5. The $1 /$ coherent domain size and positron lifetime in defects Fig. 6. The $1 /$ coherent domain size and positron lifetime in defects as a function of implantation dose in the sample with $2.36 \mathrm{wt} \% \mathrm{Cr}$ as a function of implantation dose in the sample with $8.39 \mathrm{wt} \% \mathrm{Cr}$

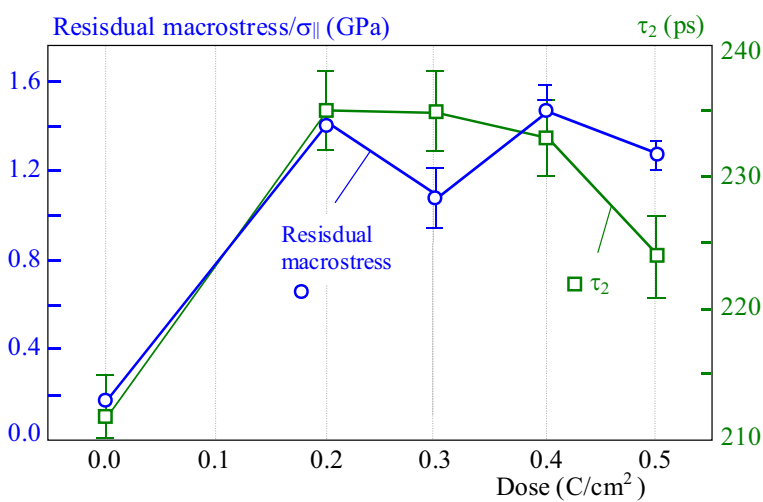

Fig. 7. Residual macrostress and positron lifetime in defects as a function of implantation dose in the sample with $2.36 \mathrm{wt} \% \mathrm{Cr}$

Based on analysis of the X-ray diffraction data by the TOPAS software, the phase transitions have not been observed. Contrary, changes of lattice parameter and inverse coherent domain size due to helium implantation have been found. As it can be seen in Figs. 3-6, the lattice parameter and inverse coherent domain size increase with the implantation dose. Similar behavior can also be seen from the PAS results describing the creation of a small vacancy cluster, the size of which saturates at a certain

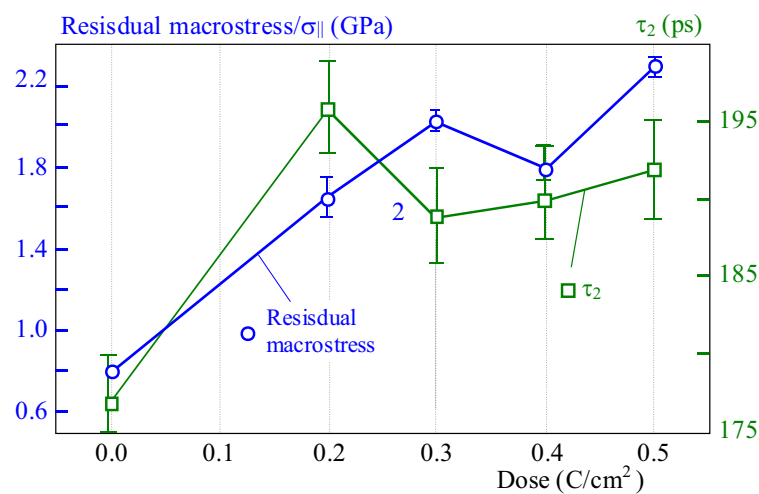

Fig. 8. Residual macrstress and positron lifetime in defects as a function of implantation dose in the sample with $8.39 \mathrm{wt} \% \mathrm{Cr}$

level of the implantation dose. Determination of residual stress was done by the GI-sin2? method. This method is used very often to determine residual stresses in depth because it is a non-destructive method. As it can be seen in Fig.7 and Fig.8, there is a rapid increase of residual stresses with increasing implantation dose.

The crystallographic texture was characterized by pole figure (110). The angle distribution of X-ray diffraction response after correction on the defocusing effect is pre- 

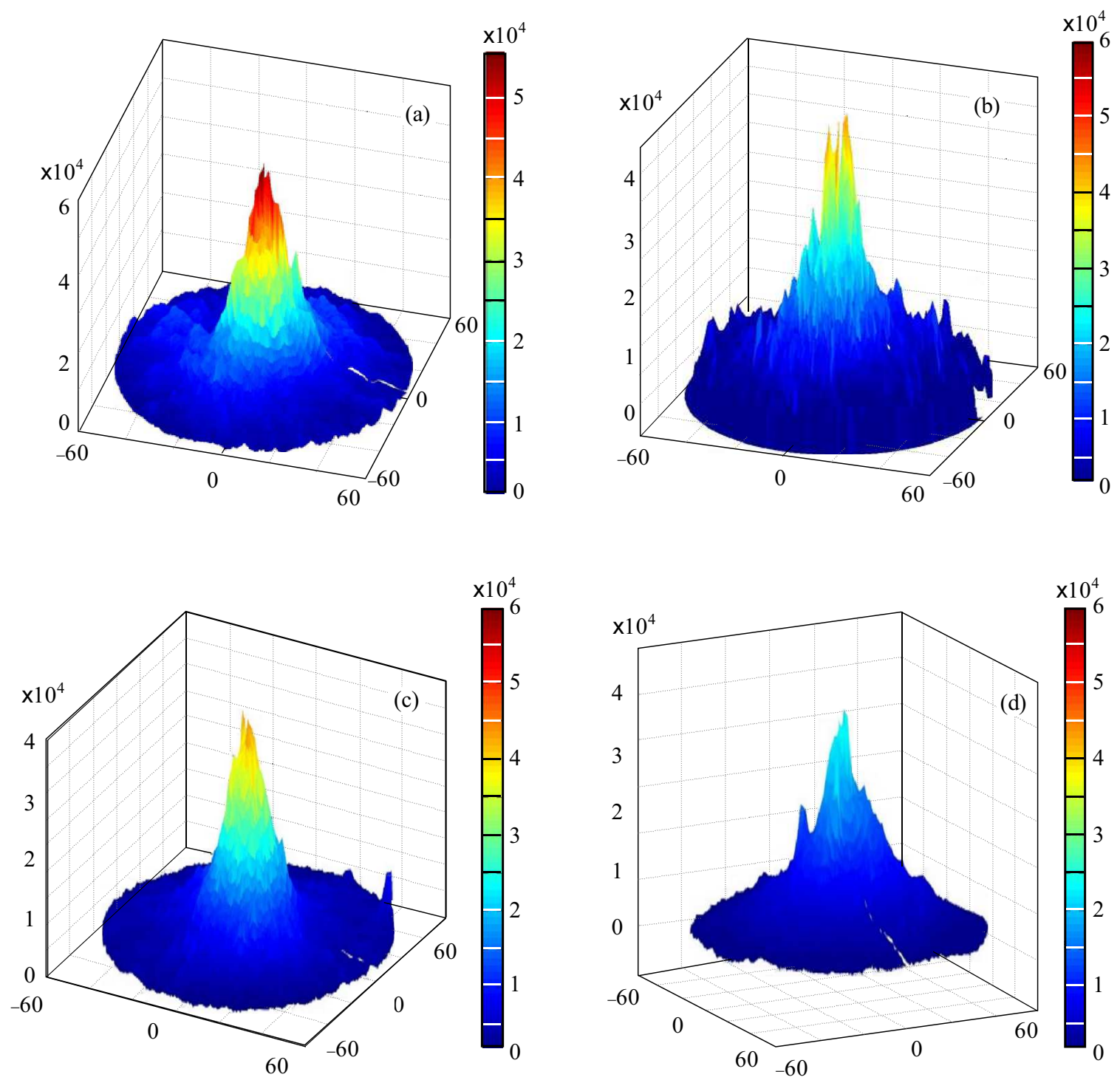

Fig. 9. Pole figure (110) of Fe-Cr alloys: (a) - non-implanted 2.36 wt\% Cr, (b) - implanted 2.36 wt\% Cr with maximum implantation dose, (c) - non-implanted $8.39 \mathrm{wt} \% \mathrm{Cr}$, (d) - implanted $8.39 \mathrm{wt} \% \mathrm{Cr}$ with maximum implantation dose. The vertical axes: The X-ray diffraction response corrected on the defocusing effect, arbitrary units. The first horizontal axes: The polar angle, grad. The second horizontal axes: The azimuthal angle, grad.

sented for investigated specimens on Fig.9. The texture in the higher $\mathrm{Cr}$ content alloy after helium implantation is the most weak. For this aspect, the specimen with 8.39 wt\% Cr has the most optimal crystallographic texture [20], because the isotropic state provides the improvement of mechanical properties of the loading steels. It corresponds to the choice of currently most perspective materials for advanced nuclear power systems.

\section{CONCLUSION}

In this work, two Fe-Cr alloys with the low and high chromium content under the different helium implantation doses were compared. XRD determination of the structural parameters has been performed after He-ion irradiation of the steel with 2.36 and $8.39 \mathrm{wt} \% \mathrm{Cr}$. The dose dependence of the lattice parameter and the coherent do- main size is observed for both specimens. A similar dose dependence of the lattice parameter, the inverse coherent domain size and the positron lifetime in defects was found. The level of residual macrostress increases due to He implantation. The texture measurement after He implantation confirmed that the steel with $8.39 \mathrm{wt} \% \mathrm{Cr}$ is an optimal material for advanced nuclear reactors. Our study showed that GIXRD in combination with PAS can be used to study sub-surface layers damaged by ion implantation.

\section{Acknowledgements}

This study was financially supported by grant of Scientific Grant Agency of the Ministry of Education of Slovak Republic, Slovak Academy Information Agency (SAIA) and the Slovak Academy of Sciences No. VEGA $1 / 0204 / 13$. 


\section{REFERENCES}

[1] FARRELL, A.: Experimental effects of helium on cavity formation during irradiationa review, Radiation Effects 53 No. 3-4 (1980), 175-194.

[2] POROLlO, S. I.-DVORIASHiN, A. M.-VOROBYEV, A N.-KONOBEEV, YU. V.: The microstructure and tensile properties of $\mathrm{FeCr}$ alloys after neutron irradiation at $400 \mathrm{C}$ to 5.57.1 dpa, Journal of Nuclear Materials 256 No. 2-3 (1998), $247-253$.

[3] KONOBEEV, YU. V.-DVORIASHIN, A. M.-POROLLO, S. I.-GARNER, F. A. : Swelling and microstructure of pure Fe and $\mathrm{FeCr}$ alloys after neutron irradiation to 26 dpa at $400 \mathrm{C}$, Journal of Nuclear Materials 355 No. 1-3 (2006), 124-130.

[4] BALLO, P.-SLUGEŇ, V. : Atomic simulation of grain-boundary sliding and migration in copper, Physical Review B 65 No. 1 (2001), 012106-012106.

[5] SLUGEŇ, V.-KURIPLACH, J.-BALLO, P.-DOMONKO, P. : Hydrogen implantation effect in copper alloys selected for ITER investigated by positron annihilation spectroscopy, Nuclear Fusion 44 No. 1 (2003), 93-97.

[6] BALLO, P.-SLUGEŇ, V.: Grain boundary sliding and migration in copper: the effect of vacancies, Computational Materials Science 33 No. 4 (2005), 491-498.

[7] BALLO, P.—DEGMOVÁ, J.-SLUGEŇ, V. : Grain boundary sliding and migration in copper: Vacancy effect, Physical Review B 72 No. 6 (2005), 064118-064118.

[8] KRŠJAK, V.-SLUGEŇ, V.-PETRISKA, M.-SOJAK, S. EGGER, W.: Microstructural study of He-implanted Fe-Cr alloys with the use of conventional lifetime technique and pulsed low energy positron beam, Physica Status Solidi C 6 No. 11 (2009), 2339-2341, Special Issue: 15th International Conference on Positron Annihilation (ICPA-15).

[9] ZIEGLER, J. F.—ZIEGLER, M. D.-BIERSACK, J. P. : SRIM The stopping and range of ions in matter (2010), Nuclear Instruments and Methods in Physics Research Section B: Beam Interactions with Materials and Atoms 268 No. 11-12 (2010), 1818-1823, 19th International Conference on Ion Beam Analysis.

[10] KOVÁČ, P.-PAVlOVIČ, M.-DOBROVODSKÝ, J. : A 0.9 MV Accelerator for Materials Research at the STU Bratislava, Nuclear Instruments and Methods in Physics Research Section B: Beam Interactions with Materials and Atoms 85 No. 1-4 (1994), 749-751.

[11] SLUGEŇ, V.-KRŠJAK, V.-EGGER, W.-PETRISKA, M. ; SOJAK, S.; VETERNÍKOVÁ, J.: FeCr alloys behavior after helium implantation, Journal of Nuclear Materials 409 No. 2 (2011), 163-166, Proceedings of the IAEA-EC Topical Meeting on Development of New Structural Materials for Advanced Fission and Fusion Reactor Materials (TR-37435).

[12] KRŠJAK, V.-SOJAK, S.-SLUGEŇ, V.-PETRISKA, M. : Ion implantation induced defects in $\mathrm{Fe}-\mathrm{Cr}$ alloys studied by conventional positron annihilation lifetime spectroscopy, Journal of Physics: Conference Series 265 No. 1 (2014), 012014-012014.

[13] BIRKHOLZ, M.: Thin Film Analysis by X-ray Scattering, Willey-VCH, Weinheim, 2006, pp. 143-290.

[14] NOVÁK, P.-DOBROČKA, E.-BÚC, D.-KOVÁČ, J. : Determination of residual stress in thin film by GIXRD, APCOM conference proceedings 1 No. 1 (2014), 300-303.

[15] GOKHMAN, A.-PECKO, S.-SLUGEŇ, V.: Cluster dynamics study of damage accumulation in helium-implanted Fe2.5at\%Cr alloy, Radiation Effects and Defects in Solids 170 No. 2 (2015), 130-137.

[16] WAS, S. G.: Fundamentals of Radiation Materials Science, Springer, Verlag, Germany, 2007, pp. 545-576.

[17] LITTLE, E. A.-STOW, D. A.: Void-swelling in irons and ferritic steels: II. An experimental survey of materials irradiated in a fast reactor, Journal of Nuclear Materials 87 No. 1 (1979), 25-39.

18] GELLES, D. S.: Microstructural examination of neutron-irradiated simple ferritic alloys, Journal of Nuclear Materials 108-9 No. 1 (1982), 515-526.

19] GARNER, F. A.-TOLOCZKO, M. B.-SENCER, B. H. : Comparison of swelling and irradiation creep behavior of fcc-austenitic and bcc-ferritic/martensitic alloys at high neutron exposure, Journal of Nuclear Materials 276 No. 1-3 (2000), 123-142.

[20] MARQUES, M. J.-PINA, J.-DIAS, A. M.-LEBRUN, J. L.-FEUGEAS, J. : X-ray diffraction characterization of ion-implanted austenitic stainless steel, Surface and Coatings Technology 95 No. 1 (2015), 8-16.

Received 3 July 2014

Patrik Novák was born in Ružomberok (Slovakia) in 1987. He is currently a researcher and a doctoral candidate at the Institute of Nuclear and Physical Engineering. He has expertise in studying properties of thin films by X-ray diffraction. His dissertation thesis deals with an analysis of residual stresses in thin films by grazing incidence X-ray diffraction. His current research is focused on the study of structural information about optoelectronic devices $(\mathrm{ZnO} / \mathrm{GaP})$. He finished his master degree at the Slovak University of Technology (2012) in physical engineering. His diploma thesis was Determination of depth profile of the phase composition of thin films by X-ray diffraction at low angle of incidence. He gained professional experience at the Slovak Academy of Sciences and the Center for Nanodiagnostics.

Aleksandr Gokhman was born in Odessa, Ukraine, in 1957. He received a master degree in theoretical physics from the Odessa State University and $\mathrm{PhD}$ degree in solid state physics from the Leningrad Polytechnical Institute, Russia. He received Dr. Sci. in solid state physics from the SanctPetersburg Technical University, Russia and in the physics of metals from the Kiev National University, Ukraine. He currently works at the Department of Physics, South Ukrainian National Pedagogical University, Ukraine. His current research is focused on the material science of thermal, mechanical and irradiated metals, alloys and semiconductors.

Edmund Dobročka was born in Nové Zámky, Slovakia, in 1955. He received MSc degree in solid state physics from the Faculty of Mathematics and Physics, Charles University in Prague. He is currently a senior scientist at the Institute of Electrical Engineering of the Slovak Academy of Sciences. His research interest is focused on X-ray diffraction analysis of structural properties of thin films.

Jozef Bokor, born in Trnava in 1988, Slovak Republic, graduated from the Slovak University of Technology in Bratislava, Faculty of Electrical Engineering and Information Technology in 2012. He is presently a PhD student at the Institute of Nuclear and Physical Engineering, FEI STU in Bratislava. His $\mathrm{PhD}$ thesis is focused on ion-optical rotating systems used in ion therapy.

Stanislav Pecko, born in Žilina, Slovakia, in 1988. He gained his master degree in Nuclear Power Engineering (2013) from the Slovak University of Technology in Bratislava. Since 2013, he is a PhD student at the Institute of Nuclear and Physical Engineering at the Slovak University of Technology in Bratislava with a focus on the degradation of reactor pressure vessel steels studied using positron annihilation spectroscopy. He is a member of the Slovak Nuclear Society (SNUS). 